some obstruction to the bile-ducts, as no bile could be detected passing with the stools, so that a pathological condition was here established analogous in its result to the experimental ligature, for in each case the escape of bile was effectually hindered. If, then, it is correct that the retention of bile within the liver prevents the formation of hepatic glycogen, it necessarily follows that the same retention must greatly diminish the amount of sugar in a case of glycosuria of that type in which the disease is chiefly dependent on a too rapid metamorphosis of glycogen into sugar. In making deductions from a single case, it is wellnigh impossible to separate the post hoc from the propter hoc; but, at any rate, in this case, coincident with the retention of bile, the amount of sugar excreted fell to zero, and remained so as long as the obstruction lasted-speedily, however, regaining its usual amount of ten grains per ounce as soon as bile was again poured into the intestines.

The whole subject of glycosuria up till now has been elucidated more by the experimental physiologist than by the physician. However valuable such experiments may be, the results obtained from them are often very fallacious, the condition under which they are conducted in many cases being far removed from anything existing in nature, so that confirmation of such observations by clinical work is always highly satisfactory. Of course the phenomena of this case may bear an interpretation differing widely from that which $I$ have assigned to them; still, I venture to think that the biliary retention being accompanied by an almost entire absence of sugar in the urine was not a mere coincidence, but that the two symptoms were related to each other as cause and effect.

Stamford-hill.

CASE OF

\section{SUPPURATING KIDNEY; NEPHROTOMY AND DRAINAGE.}

BY MICHAEL T. SADLER, M.D. LOND., \&C., HOYORARY PHYSICIAN TO THE BECKETT HOSPITAL, BARNSLEY.

E. N-, aged twenty-two, telegraph clerk, consulted me for the first time on Jan. 18th, 1885, on account of a pain in his right side. He had been ailing for about two years, and had felt more or less of the pain for about twelve months. Since November, 1884, he had lost weight and strength rather rapidly, but had not left his work. Sometimes the pain was very violent, striking up into his head and face in the form of neuralgia. There were also frequent night sweats. The pulse was usually 110 to 120 , and the temperature, even in the morning, over $100^{\circ}$. On examination, I found a tumour, which he had not noticed, in the right flank, rounded, ill-defined, semi-fluctuating, extending from the liver down within the crest of the ilium, coming in front to within two inches of the umbilicus, and passing backwards behind the dorsal muscles. The urine, on examination, proved to be albuminous, containing much pus; sp. gr. 1014 . At times the urine was for a short time clear and free from pus or albumen. There was no distinct phthisical family history. His father and one sister died of heart disease.

Having arranged for his admission into a private ward in the Beckett Hospital, on March 6th I cut down on the kidney by an incision four inches long one inch below and parallel with the last rib on the right side. On dividing the lumbar fascia about a pint of offensive curdy pus escaped, and then the finger could be passed into a cavity roughly reniform in shape, occupying the position of the tumour, apparently about eight or nine inches from above downwards, but the lower end of which could not be reached. No calculus could be felt. The cavity was washed out with carbolic lotion, and a large drainage-tube inserted.

The pain ceased to be troublesome after the operation, the hectic symptoms gradually diminished, and the appetite, which had been very poor, soon returned. The drainagetube was kept in until the 21st, the cavity being daily washed out with carbolic lotion until the $24 \mathrm{th}$, when the urine became smoky-looking, and sanitas was substituted for carbolic acid in the lotion. On April 6th he was allowed to leave his bed, and on the 19th was removed home. On the 20th he passed a small phosphatic calculus by the urethra, and on May 9th had suddenly an attack of pain in the left calf and foot, with partial obstruction of the left femoral artery. This, however, had quite passed off by the $20 \mathrm{th}$, and from that time his progress, though slow, was continuous, although the urine continued to contain pus, sometimes more and sometimes less. In July he returned to his work and was able to attend the regulation number of hours (eight daily) until March, 1886. Up to Christmas, 1885, he was free from pain, had a tolerable appetite, taking more milk than meat, and had gained flesh. There was still a discharge of pus from the opening in the loin, but the urine was free from any cloudiness. A sample examined on Nov. 11th proved, however, to be albuminous, sp. gr. 1014, alkaline, with a white deposit containing pus-cells and a few crystals of triple phosphate. He broke down under the severe weather of February and March, 1886, and died from uræmia on March 19th. No examination of the body was obtained.

\section{ABSCESS OF KIDNEY TREATED BY FRE- QUENT TAPPINGS; RECOVERY.}

\section{Br THOMAS EDWARDS, M.R.C.S., L.R.C.P., L.M.}

ON Dee. 4th, 1885, W. V-, aged twenty-three, of this village, working in London as a gravedigger, returned home complaining of constant pain of a dull aching character in the lumbar region, which he had had for the last eighteen months. He had been treated for lumbago and liver disease. The family history is good. He stated that he had never injured himself to his knowledge, and that he had "shivering fits" continually.

On examination the patient was greatly emaciated, appearing as one in the last stage of phthisis. There was pain on pressure over the right kidney, also pain on fully extending the right leg. There appeared to me deep fluctuation midway between the last rib and the crest of the ilium. Hectic fever and rigors were present; the urine was scanty and high-coloured, albuminous, but free from blood or pus ; there was also profuse diarrhoa. I inserted obliquely upwards a trocar and cannula (one I usually carry in my dressingcase) to its full length, midway between the last rib and the crest of the ilium and two inches from the spine, and drew off a tumblerful of offensive pus resembling cream.

For the following two days the patient's condition improved, but soon afterwards all the bad symptoms returned. I again tapped and drew off another half-pint of pus. I repeated this operation five times, drawing off altogether three pints and a half of pus, the last drawn being terribly offensive. On each occasion the small wound made by the trocar healed in a day or two. The patient's condition after this greatly improved; the pain, fever, and rigors disappeared; he could walk, had a good appetite, and was rapidly gaining flesh. I gave quinine throughout, but now added tincture of iron and cod-liver oil. About three weeks after the last tapping the patient complained of an uncomfortable feeling in the old place, but no pain. I again tapped, and drew off three pints of clear amber-coloured fluid resembling urine; this operation I repeated several times, but on each occasion less came away, until it disappeared. The patient has quite regained his health and strength, taking long walks daily. Urine normal. Harrold, Beds.

Liverpool Southern Hospital-On the 11th inst. the Duke of Connaught, who accompanied Her Majesty in her recent visit to Liverpool, visited this hospital, which fourteen years ago he had formally opened. An address was presented to the distinguished visitor, in which it was stated that since its opening 107,000 persons had received at it medical or surgical aid. After inspecting the various wards, the Duke gave the name of the "Margaret Ward" to the apartment occupied by the children, and expressed his great satisfaction with the arrangement and management of the institution.

Is St. Pancras on Sunday last, the fourth annual United Friendly Societies' demonstration and church parade in aid of the funds of the West London and University College Hospitals took place, in the presence of a large number of persons. Collection boxes were exhibited along the route taken by the procession, and a substantial sum is said to have been collected. 